\title{
Antifungal Potential of Aqueous Extract of Boswellia carteri
}

\author{
Al-Otibi Fatimah ${ }^{1 *}$ (D), Raedah Ibrahim Alharbi ${ }^{1}$ (D), Gadah Albasher ${ }^{2}$ (D), \\ Rafa Almeer $^{2}$ iD and Nura Sulaiman Alsaggabi ${ }^{1}$ i
}

${ }^{1}$ Department of Botany and Microbiology, College of Science, King Saud University, P.O. Box 22452, Riyadh 11495, Kingdom of Saudi Arabia. '2Department of Zoology, College of Science, King Saud University, P.O. Box 22452, Riyadh - 11495, Kingdom of Saudi Arabia.

\begin{abstract}
To assess the antifungal activity of the crude aqueous extract of $B$. carteri. Three independent concentrations $(1 \%, 2.5 \%$, and $5 \%)$ of the crude aqueous extract of $B$. carteri were tested for their in vitro activity against selected fungal strains. The treated ( $5 \%$ concentration) and untreated $A$. alternata samples were analyzed for morphological changes using scanning electron microscopy (SEM). FourierTransform Infrared (FTIR) spectrometry of the extract was done to identify the phytoconstituents responsible for the antifungal activity. Results showed that the crude aqueous extract of $B$. carteri inhibited the growth of all the selected fungal species. The percentage of mycelial growth of the tested fungi decreased as the concentration of the aqueous extract increased from $1 \%$ to $5 \%$. SEM-based studies of $A$. alternata treated with $\mathbf{5 \%}$ showed significant morphological changes including shrunken hyphae, membrane disintegration, and distorted conidial structures compared to the untreated fungal cells. The crude aqueous extract of $B$. carteri has the potential to be used as a natural and effective fungicidal agent for controlling the growth of pathogenic fungi.
\end{abstract}

Keywords: Antifungal activity; Aqueous extract; Boswellia carteri; FTIR; Plant pathogenic fungi; Scanning electron microscopy.

\footnotetext{
*Correspondence: falotibi@ksu.edu.sa; +966-8055970

(Received: 06 November 2019; accepted: 03 December 2019)

Citation: Al-Otibi Fatimah, Gadah Albasher, Raedah Ibrahim Alharbiand Nura Sulaiman Alsaggabi, Antifungal Potential of Aqueous Extract of Boswellia carteri, J Pure App/ Microbiol., 2019; 13(4):2375-2381. https://doi.org/10.22207/JPAM.13.4.53

C The Author(s) 2019. Open Access. This article is distributed under the terms of the Creative Commons Attribution 4.0 International License which permits unrestricted use, sharing, distribution, and reproduction in any medium, provided you give appropriate credit to the original author(s) and the source, provide a link to the Creative Commons license, and indicate if changes were made.
} 


\section{INTRODUCTION}

Boswellia carteri (B. carteri; also known as Birdwood or Birdw) is a moderate-to-large sized endemic tree mostly found in the dry mountainous regions of Somalia, Saudi Arabia, Sudan, and Yemen ${ }^{1}$. The extracts from Boswellia species have been widely plethora of conditions such as asthma, arthritis, rhinitis, analgesic effect, gastric $\&$ hepatic disorders, skin diseases, cancer as well as inflammatory associated diseases in human ${ }^{2-6}$.

The plants of Boswellia species are a rich source of natural resins and several bioactive compounds ${ }^{7-9}$. Moreover, essential oils extracted from $B$. carteri have been reported to exhibit antifungal activity against Candida species ${ }^{10}$, Stachybotrys chartarum, ${ }^{11}$ Trichotecium roseum ${ }^{11}$, and toxigenic Aspergillus species $^{11-14}$. Alternaria alternata (A. alternata) is an opportunistic fungus that causes leaf spots and blights of many economically important plants ${ }^{15}$. Helminthosporium rostratum ( $H$. rostratum) is a saprobic fungus that infects several plants including corn, rice, maize, millet, and sorghum ${ }^{16}$. Fusarium solani (F. solani) is a filamentous fungus known to infect several crops including beans, cucurbits, potatoes, and peas ${ }^{17}$.

Although the antifungal activity of Boswellia species has been well documented ${ }^{11-14}$, the antifungal activity of the aqueous extract of $B$. carteri against $A$. alternata, $H$. rostratum, and F. solani remains elusive. Therefore, the present study was designed to assess the antifungal properties of crude aqueous extracts of $B$. carteri against three plant pathogenic fungi (A. alternata, $H$. rostratum, and $F$. solani). Furthermore, scanning electron microscopic (SEM) and Fouriertransform infrared (FTIR) spectroscopic studies were undertaken to characterize the antifungal attributes of $B$. carteri.

\section{MATERIALS AND METHODS Sample Collection}

The oleo-gum resin of $B$. carteri was procured from authorized suppliers (Bin mingash store, Riyadh, Saudi Arabia), or collected from the plant (B. carteri) grown in the region of Riyadh, Saudi Arabia. The sourced plant material was stored overnight at $-80^{\circ} \mathrm{C}$. The collected gum resins were powdered using mortar, pestle, blender, and electric sieve. The powdered resins were stored at $-20^{\circ} \mathrm{C}$ until further use.

\section{Preparation of Crude Aqueous Extract}

Briefly, $30 \mathrm{~g}$ of the crushed material was soaked for 24 hours in $300 \mathrm{~mL}$ distilled water $(10 \%$ $\mathrm{w} / \mathrm{v}$ ) at room temperature $\left(37^{\circ} \mathrm{C}\right)$. The soaked material was macerated with $50 \mathrm{~mL}$ distilled water $(10 \% \mathrm{w} / \mathrm{v})$ in a conical flask and kept in an orbital shaker ( $250 \mathrm{rpm}$ at $45^{\circ} \mathrm{C}$ for 24 hours). The extracts were then concentrated and dried under reduced pressure and $40^{\circ} \mathrm{C}$ using a rotary evaporator (Rotavapor $\left.{ }^{\circledR} \mathrm{R}-215, \mathrm{BUCHI}\right)$. All the filtered extracts were preserved aseptically in glass bottles at $4^{\circ} \mathrm{C}$ until further use.

Three concentrations of the aqueous extract $(1,2.5$, and $5 \mathrm{mg} / \mathrm{mL})$ were prepared using sterile aqueous extracts and with distilled water $(10 \% \mathrm{w} / \mathrm{v})$. The reconstituted aqueous extracts were passed through $0.45 \mu \mathrm{M}$ bacterial filter papers (Millipore Inc., Riyadh, Saudi Arabia) prior to using them for in vitro studies.

\section{Fungal specimens}

Fungal strains of $A$. alternata, $H$. rostratum, and F. solani were obtained from the Department of Plant Protection, College of Food and Agricultural Sciences, King Saud University, Riyadh, Saudi Arabia. Fungal isolates were maintained on potato dextrose agar, stored at $4^{\circ} \mathrm{C}$ and subcultured once a month.

\section{Antifungal screening}

Antifungal activity was determined using the poisoned food technique ${ }^{18}$. One milliliter $(\mathrm{mL})$ of the aqueous extract $(1 \%, 2.5 \%$, and $5 \%$ ) was aseptically poured into sterile petri dishes $(9 \mathrm{~cm}$ in diameter) followed by the addition of $19 \mathrm{~mL}$ of molten potato dextrose agar. After solidification of the medium, mycelial plugs ( $6 \mathrm{~mm}$ in diameter) of A. alternata, $H$. rostratum, and $F$. solani from the periphery of 9 days old culture were aseptically inoculated into the center of the petri dishes and incubated at $25 \pm 2^{\circ} \mathrm{C}$ for 7 days. Plates without extract served as controls. The experiments were carried out in triplicates. Percent reduction of mycelial growth was measured using the formula: $\%$ inhibition $=(A C-A T) / A C^{\prime} 100$

Where $A C=$ mean diameter of the mycelial growth in the control plate; AT = mean diameter of the mycelial growth in the treatment plate $^{19}$. 


\section{Scanning Electron Microscopic Analysis}

The morphological changes induced by the extract was assessed using SEM. In brief, small agar pieces $(6 \mathrm{~mm})$ were aseptically cut from the inhibition zone and fixed in $2.5 \%(\mathrm{v} / \mathrm{v})$ glutaraldehyde buffered with $0.1 \mathrm{M}$ sodium phosphate buffer ( $\mathrm{pH}$ 7.4). The suspension was centrifuged after 48 hours, rinsed thrice with phosphate-buffered saline, and was dehydrated through sequential ethanol washes (60 \% - 100\%). The dehydrated specimens were freeze-dried and mounted onto stubs using double-sided carbon tape, and then coated with a thin layer of gold. The processed specimens were finally examined under a scanning electron microscope (JSM 6060LV JEOL, Japan LTD).

\section{Structural Characterization by Fourier-Transform Infrared Spectrometry}

The dried powder of the aqueous extract of $B$. carteri was used for Fourier-Transform Infrared (FTIR) analysis. In brief, $10 \mathrm{mg}$ of the dried extract was encapsulated in $100 \mathrm{mg}$ of $\mathrm{KBr}$ pellet. The resulting pellet was loaded in the FTIR spectrophotometer (Nicolet 6700, Thermo Scientific, USA) equipped with a beam splitter, a detector (DTGS) and OMNIC software to generate the FTIR spectra in the mid-region of $500-4000$ $\mathrm{cm}^{1}$.

\section{Statistical Analysis}

The data are expressed as mean and standard deviation (SD). Significant differences were analyzed using one-way analysis of variance (ANOVA). $p$-value $<0.05$ was considered statistically significant. As the overall mean difference between the three groups was not significant, post-hoc test was not required.

\section{RESULTS}

Antifungal Activity of the Aqueous Extract of $B$. carteri

The crude aqueous extract of $B$. carteri showed mild inhibition at $1 \%$ concentration against all three fungal strains (A. alternata, $H$. rostratum, and $F$. solani), with a percentage inhibition ranging
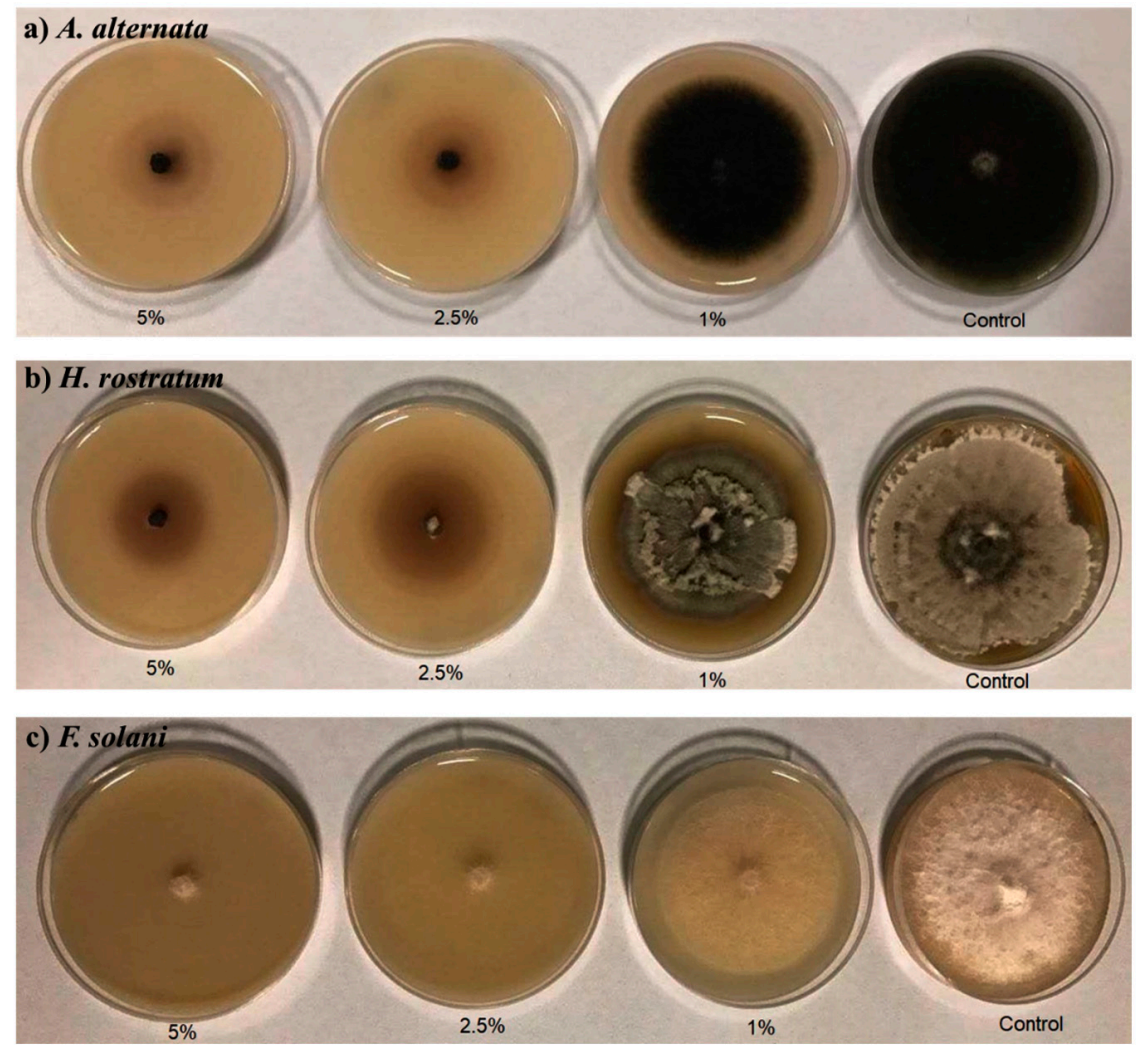

Fig. 1. In vitro activity of aqueous extract of Boswellia carteri on three phytopathogenic fungi; 1a) A. alternata, 1b) H. rostratum and 1c) F. solani 
from $18.1 \%$ against $F$. solani to $22.3 \%$ against $H$. rostratum. At $2.5 \%$ concentration, it exhibited mild activity against $F$. solani (22.9\%), while, it exhibited moderate activity against $H$. rostratum (36\%), and $A$. alternata (57.3\%). At 5\% concentration, it induced moderate inhibition of all three fungal species (Table 1 and Fig. 1a to 1c).

\section{Scanning Electron Microscopy}

The microphotographs of the untreated mycelia (controls) of $A$. alternata showed normal tubular structure with intact mycelia (Fig. 2a). The treated A. alternata mycelia appeared distended, flaccid and showed condensed hyphal branches with a rough and wrinkled surface (Fig. 2b). Similarly, distorted structures were noted for $H$. rostratum and $F$. solani treated with the aqueous extract of $B$. carteri (results not shown).

\section{Fourier-Transform Infrared Spectroscopic Analysis of the Aqueous Extracts}

FTIR analysis of the crude aqueous extract of $B$. carteri showed the presence of various important functional groups. The IR spectrum showed strong absorption peaks at 3447, 2931, 1716, 1656, 1459, 1379, 1244, 1172, 1035, 891, $725,614,441$, which corresponds to alcohol, carboxylic acid, ester, alkene, alkane and alkyl amine, alkyl halides, halogen and cycloalkane functional groups (Fig. 3).

\section{DISCUSSION}

This study showed that the aqueous extract of $B$. carteri exhibited potent in vitro activity against $A$. alternata, $H$. rostratum, and $F$. solani. SEM confirmed the presence of
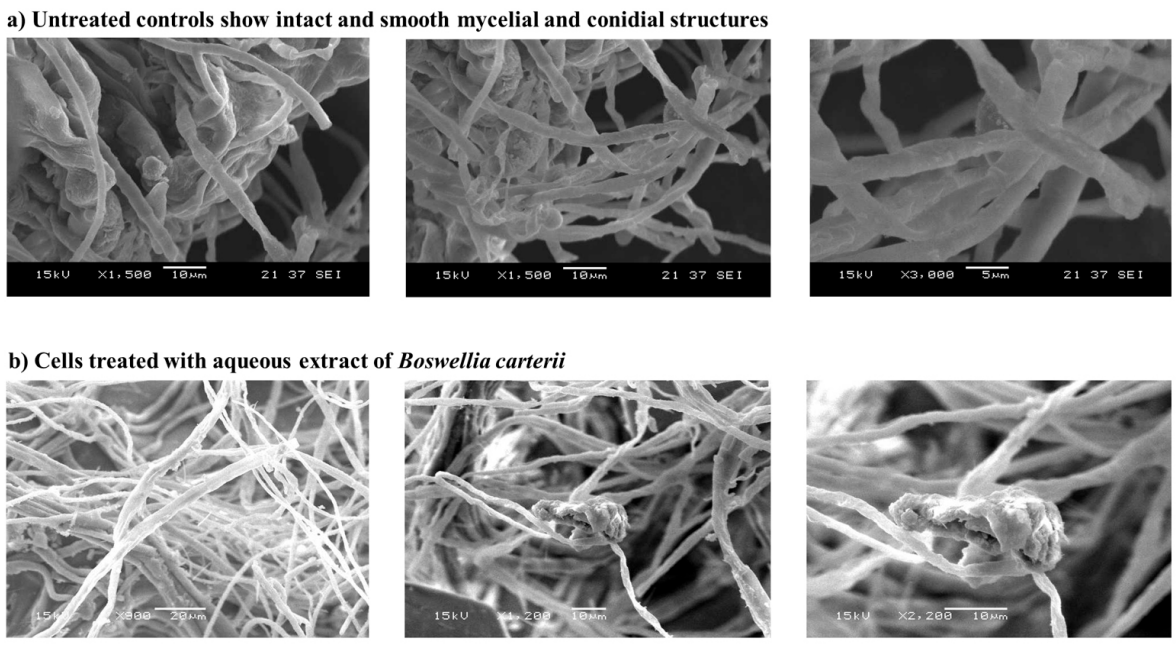

Fig. 2. Scanning electron microphotographs of Alternaria alternata; a) Untreated controls show intact and smooth mycelial and conidial structures, and b) Cells treated with aqueous extract of Boswellia carteri.

Table 1. Antifungal activity of the aqueous extract of Boswellia carteri

\begin{tabular}{|c|c|c|c|c|c|c|}
\hline & \multicolumn{2}{|c|}{$\begin{array}{l}\text { Alternaria } \\
\text { alternata }\end{array}$} & \multicolumn{2}{|c|}{$\begin{array}{l}\text { Helminthosporium } \\
\text { rostratum }\end{array}$} & \multicolumn{2}{|c|}{$\begin{array}{l}\text { Fusarium } \\
\text { solani }\end{array}$} \\
\hline & $\begin{array}{l}\text { Growth } \\
(\mathrm{mm})\end{array}$ & $\begin{array}{c}\text { Inhibition } \\
\%\end{array}$ & $\begin{array}{l}\text { Growth } \\
\text { (mm) }\end{array}$ & $\begin{array}{c}\text { Inhibition } \\
\%\end{array}$ & $\begin{array}{l}\text { Growth } \\
(\mathrm{mm})\end{array}$ & $\begin{array}{c}\text { Inhibition } \\
\%\end{array}$ \\
\hline Control & $8.0(0.00)$ & 0.0 & $8.0(0.00)$ & 0.0 & $8.0(0.00)$ & 0.0 \\
\hline $1.0 \%$ & $6.4(0.06)$ & 19.6 & $6.2(0.08)$ & 22.3 & $6.6(0.09)$ & 18.1 \\
\hline $2.5 \%$ & $3.4(0.20)$ & 57.3 & $5.1(0.03)$ & 36.0 & $6.2(0.14)$ & 22.9 \\
\hline $5.0 \%$ & $3.3(0.08)$ & 58.4 & $4.2(0.08)$ & 47.3 & $4.5(0.50)$ & 43.8 \\
\hline
\end{tabular}

Values are presented as means (SD) of triplicates. 


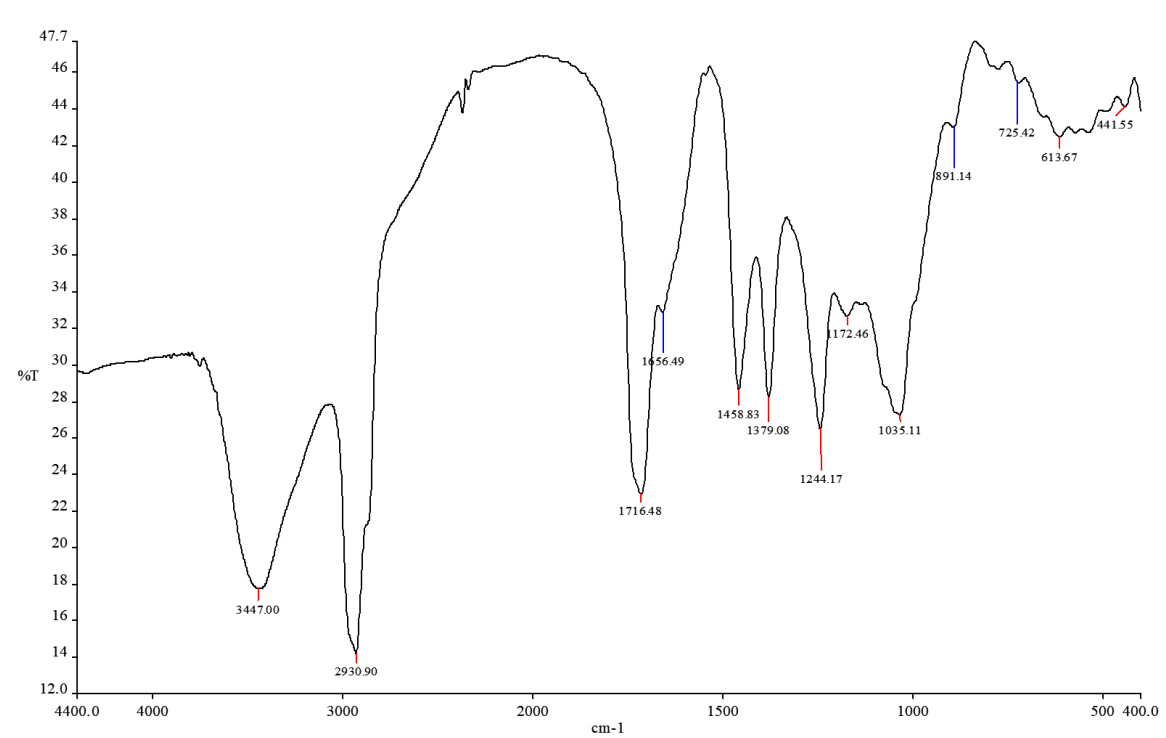

FTIR, Fourier-transform infrared.

Fig. 3. FTIR spectrum of the aqueous extract of Boswellia carteri

ultrastructural changes in the mycelia treated with the extract compared with the untreated mycelia. FTIR spectroscopy of the extract showed the presence of various aliphatic and aromatic compounds, which could be responsible for the antifungal activity.

Chemical pesticides have widely been used in contemporary agriculture to control various plant diseases including those caused by pathogenic fungi ${ }^{20}$. However, the lethal effect exerted by the synthetic fungicides on the soil microbiota, plants, and water coupled with the development of fungicide resistance highlights the need for the development of natural and effective antifungals for combating fungal infections. Plant-based antifungals offer an eco-friendly and effective alternative to conventional synthetic fungicides ${ }^{21}$.

The arid and semi-arid regions of the Middle East is the home for many medicinal plants ${ }^{22}$. B. carteri is one of the valuable medicinal plants distributed in the dry mountain areas of the Middle East ${ }^{1}$. Metabolites derived from oleogum resin have been used in the management of myriads of plant diseases ${ }^{23}$. However, there is a paucity of studies exploring the antifungal activity of $B$. carteri $i^{11,13}$. In the current study, three different concentrations ( $1 \%, 2.5 \%$, and $5 \%)$ of the crude aqueous extract of $B$. carteri were screened against three phytopathogenic fungal species ( $A$. alternata, $H$. rostratum, and $F$. solani). With subtle exceptions, the extract of $B$. carteri showed mild activity at lower concentrations ( $1 \%$ and $2.5 \%$ ) and moderate activity at $5 \%$ concentration against the three fungal species tested. The variations in the antifungal activity of the crude aqueous extract may be due to the differences in concentrations of the bioactive compounds (aliphatic and aromatic compounds) in the crude extract. Other factors ascribed for the differential activity include the extraction method, $\mathrm{pH}$, solubility, volatility, diffusion characteristics in the growth medium, and the tested fungal species ${ }^{1,24}$.

The SEM photographs of the fungal mycelia treated with the crude aqueous extract of $B$. carteri showed structural alterations in the mycelial and conidial structures compared with the untreated mycelia, thereby endorsing the antifungal activity of the crude aqueous extract. In general, crude aqueous extracts are a rich source of several bioactive compounds. Exposure to such extracts may result in cellular deformation by inducing loss of water, electrolytes and other vital intracellular components essential for the survival of the fungal cells. The phytochemical screening of crude extract using FTIR spectroscopy revealed the presence of diverse bioactive compounds (aliphatic and aromatic) which could play a vital 
role in inhibiting the growth of the fungal species.

The antifungal activity of Boswellia species is well established ${ }^{25-27}$. In the Chaurasia et al. study, the ethanolic extract of $B$. serrata showed the highest activity against Colletotrichum falcatum compared with chloroform extract. Conversely, the aqueous extract did not show any activity against Colletotrichum falcatum. ${ }^{25}$ In another study, B. serrata essential oil was found to inhibit the growth of an array of fungal species (Aspergillus brassicola [A. brassicola], A. geophila, A. fumigatus, A. ochraceous, A. terreus, Curvularia tetramera, F. equiseti, F. lateritium, F. oxysporum, F. udum, F. verticillioides, Penicillium citrinum $[P$. citrinum], and $P$. expansum) except $A$. flavus and A. tamarii $^{27}$. Similarly, the methanolic extract and fractions and sub-fractions of $B$. dalzielii stem bark were found to exhibit the activity against Candida albicans (C. albicans), P. notatum, and A. niger. ${ }^{26}$ Limited studies have assessed the antifungal activity of $B$. carteri ${ }^{11,13}$. A Serbian study investigating the antifungal potential of $B$. carteri essential oils showed variable inhibition of the tested fungal species (A. niger, Stachybotrys chartarum [S. chartarum], and Trichotecium roseum [T. roseum]). While $S$. chartarum and $T$. roseum were the most sensitive fungal isolates, A. niger was found to be least susceptible ${ }^{11}$. In another study, essential oil from $B$. carteri inhibited the growth of $A$. niger, $C$. albicans, and C. neoformans ${ }^{13}$. The antifungal activity of the essential oil of $B$. carteri was due to the presence of limonene (22.4\%), b-caryophyllene (22.2\%), $p$-cymene $(10.0 \%), d$-cadinene $(9.4 \%)$, and a-copaene $(4.8 \%)^{13}$. In line with these findings, FTIR analysis of the crude aqueous extract of $B$. carteri in the present study showed the presence of several bioactive aliphatic and aromatic compounds (alcohol, carboxylic acid, ester, alkene, alkane and alkyl amine, alkyl halides, halogen and cycloalkane), which may account for the antifungal activity against $A$. alternata, $H$. rostratum, and $F$. solani.

\section{CONCLUSION}

The crude aqueous extract of $B$. carteri has great potential as a natural antifungal in the treatment of plant phytopathogenic fungi. However, further studies are required to understand the molecular mechanism by which $B$. carteri extract inhibits the growth of the fungal mycelia.

\section{ACKNOWLEDGEMENTS}

This research project was supported by a grant from the financial support from the Researchers Supporting Project number (RSP2019/114), King Saud University, Riyadh, Saudi Arabia. The author would like to extend sincere appreciation for funding this work.

\section{CONFLICTS OF INTEREST}

The authors declare that there is no conflict of interest.

\section{FUNDING}

This study received grant-in-aid from the Researchers Supporting Project number (RSP2019/114), King Saud University, Riyadh, Saudi Arabia.

\section{AUTHOR'S CONTRIBUTION}

All authors listed have made a substantial, direct and intellectual contribution to the work, and approved it for publication.

\section{DATA AVAILABILITY}

All datasets obtained or studied during this study are incorporated in the manuscript.

\section{ETHICS STATEMENT}

This study did not involve human subjects or animals. Therefore, ethics committee approval was not required for this study.

\section{REFERENCES}

1. Mohammed AME. Estimation of active components in gum Arabic collected from western Sudan. Int. J. Sci. Res., 2015; 6(3): ART20171695.

2. Asad M and Alhomoud M. Proulcerogenic effect of water extract of Boswellia sacra oleo gum resin in rats. Pharm Biol., 2016; 54(2): 225-30. https://doi.org/10.3 109/13880209.2015.1028553

3. Mannino G, Occhipinti A and Maffei ME. Quantitative determination of 3-0-acetyl-11-keto-beta boswellic acid (AKBA) and other boswellic acids in Boswellia sacra Flueck (syn. B. carteri Birdw) and Boswellia serrata Roxb. Molecules, 2016; 21(10). https://doi. org $/ 10.3390 /$ molecules 21101329

4. Siddiqui MZ. Boswellia serrata, a potential antiinflammatory agent: an overview. Indian J. Pharm 
Sci., 2011; 73(3): 255-61.

5. Togni S, Maramaldi G, Bonetta A, et al. Clinical evaluation of safety and efficacy of Boswellia-based cream for prevention of adjuvant radiotherapy skin damage in mammary carcinoma: a randomized placebo controlled trial. Eur. Rev. Med. Pharmacol. Sci., 2015; 19(8): 1338-44.

6. Wang $\mathrm{Q}$, Pan $\mathrm{X}$, Wong $\mathrm{HH}$, et al. Oral and topical boswellic acid attenuates mouse osteoarthritis. Osteoarthr Cartilage, 2014; 22(1): 128-32. https://doi. org/10.1016/j.joca.2013.10.012

7. Hamidpour M, Hamidpour R, Hamidpour $S$ and Hamidpour R. Chemistry, pharmacology and medicinal property of Frankincense (Boswellia species): from the selection of traditional applications to the novel phytotherapy for the prevention and treatment of serious diseases. GJMR, 2015; 15: 1-9. https://doi. org/10.5348/ijcri-201458-RA-10013

8. Kooti W, Servatyari K, Behzadifar M, et al. Effective medicinal plant in cancer treatment, part 2: Review study. J Evid Based Complementary Altern Med., 2017; 22(4): 982-95. https://doi. org/10.1177/2156587217696927

9. Rashan L, Hakkim F, Idrees M, et al. Boswellia gum resin and essential oils: Potential health benefits \&\#8722; An evidence based review. Int. J. Nutr. Pharmacol. Neurol. Dis., 2019; 9(2): 53-71. https://doi.org/10.4103/ ijnpnd.ijnpnd_11_19

10. Nikolic M, Smiljkovic M, Markovic T, et al. Sensitivity of clinical isolates of Candida to essential oils from Burseraceae family. EXCLI J. 2016; 15: 280-9.

11. Stupar M, Kostic M, Savkovic, et al. Succeptibility of some fungi to Boswellia carteri Birdw. essential oil. Zbornik Matice srpske za prirodne nauke., 2016; 130: 19-27. https://doi.org/10.2298/ZMSPN1630019S

12. El-Nagerabi PS, Elshafie A, AIKhanjari S, et al. Biological activities of Boswellia sacra extracts on the growth and aflatoxins secretion of two aflatoxigenic species of Aspergillus species. Food Control, 2013; 34: 763-9. https://doi.org/10.1016/j.foodcont.2013.06.039

13. Powers CN, Osier JL, McFeeters RL, et al. Antifungal and cytotoxic activities of sixty commercially-available essential oils. Molecules, 2018; 23(7). https://doi. org/10.3390/molecules23071549

14. Prakash B, Mishra PK, Kedia A and Dubey NK. Antifungal, antiaflatoxin and antioxidant potential of chemically characterized Boswellia carterii Birdw essential oil and its in vivo practical applicability in preservation of Piper nigrum L. fruits. LWT - Food Sci. Technol., 2014; 56(2): 240-7. https://doi.org/10.1016/j.lwt.2013.12.023

15. Chung KR. Stress response and pathogenicity of the necrotrophic fungal pathogen Alternaria alternata. Scientifica, 2012; 2012: 635431. https:// doi.org/10.6064/2012/635431

16. Imrani N, Boudoudou H, Mouria A, et al. Pathogenicity of Helminthosporium rostrata on rice varieties widely grown in Morocco. IJEAB. 2017; 2: 1003-6. https://doi. org/10.22161/ijeab/2.2.58

17. Luginbuhl S. Fusarium solani: A class project for PP728 soil borne plant pathogens. Fall. 2010.

18. Grover R and Moore J. Toxicometric studies of fungicides against brown rot organisms Sclerotinia fructicola and S. laxa. Phytopathol., 1962; 52(876-80).

19. Otibi FA and Rizwana H. Chemical composition, FTIR studies, morphological alterations, and antifungal activity of leaf extracts of Artemisia sieberi from Saudi Arabia. Intl. J. Agric. Biol., 2019; 21: 1241-48.

20. Zaker M. Natural plant products as eco-friendly fungicides for plant diseases control- a review. The Agriculturists, 2016; 14: 134. https://doi.org/10.3329/ agric.v14i1.29111

21. Martinez J. Natural fungicides obtained from plants. 2012.

22. Batanouny K. Plants in the deserts of the Middle East. 2001. https://doi.org/10.1007/978-3-662-04480-3

23. Hussein RA and El-Anssary AA. Plants secondary metabolites: The key drivers of the pharmacological actions of medicinal plants, herbal medicine, Philip F. Builders, IntechOpen, https://doi.org/10.5772/ intechopen.76139

24. Gillitzer P. Optimization of screening of native and naturalized plants from Minnesota for antimicrobial activity. J. Med. Plants Res., 2012; 6. https://doi. org/10.5897/JMPR10.710

25. Chaurasia A and Gharia A. Antifungal activity of medicinal plant Boswellia serrata. J. Ultra Chem., 2017; 13(4): 88-90. https://doi.org/10.22147/juc/130403

26. Kafuti $Y$, Ojerinde $O$, Balogun $O$, et al. Antifungal evaluation and phytochemical screening of methanolic extract and fractions of Boswellia dalzielii stem bark. JPB, 2017; 14: 62. https://doi.org/10.4314/jpb.v14i1.8

27. Venkatesh HN, Sudharshana TN, Abhishek RU, et al. Antifungal and antimycotoxigenic properties of chemically characterised essential oil of Boswellia serrata Roxb. ex Colebr. Int. J. Food Prop., 2017; 20(sup2): 1856-68. 